\title{
System for Real-time Measurement and Monitoring of Forging Force of Screw-forming Machine
}

\author{
Yuan-Ming Cheng* \\ Department of Intelligent Robotics, National Pingtung University, Pingtung 90004, Taiwan, Republic of China
}

(Received June 3, 2021; accepted November 9, 2021)

Keywords: screw, screw-forming machine, force sensor, real time measurement

Screws are commonly used fasteners. In general, the term "fastener" refers to machine components comprising screws and bolts used to affix two or more components together. Screw production consists of three steps, namely, heading, threading, and coating. During the forming process, the mold used may be damaged as a result of defects in the metal wire or metal bar. In this study, we employed the CBF-43S screw-forming machine developed by Chun Zu Machinery Industry as the monitoring target and performed kinetic analysis on the slider-crank mechanism of the machine using the provided parameters. Subsequently, the forging force of the machine was measured by a force sensor and its real time changes were recorded. When an error value was identified, the machine was immediately shut down and the mold was inspected for damage. Through this method, the detrimental effect of damaged molds on the quality of screws and bolts can be prevented.

\section{Introduction}

Screws are small fasteners commonly used in machinery, electric appliances, and buildings and are thus are mass-produced to reduce costs. Screw forming consists of three steps, namely, heading, threading, and coating. The raw materials of common and larger screws are coiled metal wires and metal bars, respectively. The raw materials are first cut into suitable lengths for processing in accordance with the designated screw size. Heading, the cold processing applied to manufacture the screw head, is then conducted. The term "fastener" refers to the role of screws and nuts as machine components that affix two or more components together. Fasteners are commonly manufactured by cold forging involving continuous multipass procedures and a horizontal stamping press. Simple fastener heads are manufactured using heading machines, whereas complex fastener heads are manufactured by multipass machining. DEFORM software is generally employed in the design and analysis of fastener manufacturing in academia and industry. This software uses the finite element method to simulate the metal manufacturing process in a mold. After manufacturing design and analysis using the software, the screw must be produced using a forming machine prior to mass production.

${ }^{*}$ Corresponding author: e-mail: Chengym@mail.nptu.edu.tw https://doi.org/10.18494/SAM.2021.3722 
The forging process of fasteners includes wire rolling, wire coiling, heading, and thread rolling. During heading, the wire is first fed into a cutting mold to cut it into set lengths. Subsequently, segments of the cut wire are clamped and introduced to a die. The heading process is complete when the heading die is forged. This is an example of forging processing, that is, a process in which a stamping or extrusion mold is used to mold the shape of a forging piece into another shape. During screw production, metallic or nonmetallic foreign matter in the metal wire or bar material can result in product defects, such as steel ingot, crystal, and stomatal segregation. The inhomogeneity of the materials used in the forging process results in damage to the mold. When a mold is damaged, the produced workpieces are regarded as defects. Therefore, the forging force must be monitored in real time to identify changes and any error values; if such values are identified, the machine must be shut down and human inspection must be performed to examine for mold damage. However, machine shutdown after the identification of minor error values reduces the overall production speed. Therefore, the forging force must be monitored and adjusted to achieve optimal production.

Taiwan's fastener industry has for decades contributed to the development of the automobile industry, aerospace industry, and the so-called $3 \mathrm{C}$ products. With advancements in technology, the fastener industry has moved toward the production of high-precision and lightweight products, expanding the applications of fastener products and increasing operator profits as a result of increases in the unit price and added value of products. Therefore, increasing the manufacturing precision and decreasing the weight of fasteners have become key goals in the fastener industry.

The current commercial production-monitoring systems for fastener production employ cavity pressure measurement technology, in which a piezoelectric cavity pressure sensor is used to capture precise and dynamic measurements of the pressure curve throughout the fastener production process and determine the optimal production parameters. Through the use of this technology, operators can distinguish between acceptable- and poor-quality components. Owing to the small size of screw components, the installed piezoelectric cavity pressure sensor must be compatible with precision manufacturing technology.

Scholars have explored the use of different sensors in production-monitoring systems. Hsia et al. ${ }^{(1)}$ analyzed the problems encountered in increasing the number of piezoelectric sensor units used for monitoring. They developed a low-cost piezoelectric unit applicable in limited spaces and tested the forging force measurement performance of the unit on a five-stage forming machine; the testing results conformed to the plastic forming theory. Yoneyama ${ }^{(2)}$ proposed a pressure sensor to measure the compressive contact force. In Ref. 3, friction testing equipment was developed to test the pressure and frictional stress along a workpiece surface. The testing principles of these two studies were further analyzed, in which a hot-forging sensor prototype and a detailed design method were introduced. The acoustic emission (AE) technique is a prospective lossless audio online detection method applicable for identifying damage in the metal forming process. Mukhopadhyay et al. ${ }^{(4)}$ employed AE signals to effectively inspect the surface characteristics of a workpiece during hot forging and to optimize the sensor position. They installed three sensors on the top beam, bottom beam, and bottom mold of a press-brake bending machine to simultaneously record the acoustic signals emitted during bending. El-Galy 
and Behrens ${ }^{(5,6)}$ used AE for the real time monitoring of hot die forging processes and conducted experiments under various thermal loading conditions (i.e., temperatures, strain conditions, and strain rates). They also explored the effects of the machine noise and sensor position on the monitoring performance and analyzed the experimental results. Behrens et al. ${ }^{(7)}$ investigated the feasibility of employing the AE technique for the online monitoring of the cold forging of casehardening steel. The energy, impact, and amplitude distributions recorded through AE were assessed and compared with actual cracks and tool wear. In addition, Glaeser et al. ${ }^{(8,9)}$ installed a remote monitoring system on the cold header of an automobile fastener factory. The monitoring system provided a noninvasive method for recording vibrations and tool wear. Because the machine emitted different vibration signals when producing different components, the produced components had to be classified first. The current research status in the field of using AE technology to monitor the cold forging process has recently been reviewed. ${ }^{(10)}$ The integration of $\mathrm{AE}$ and machine learning (ML) algorithms to monitor quality was also reviewed and discussed.

In this study, we employed the CBF-43S screw-forming machine (Chun Zu Machinery Industry) in Fig. 1 as the monitoring target and conducted kinematic analysis on the slider-crank mechanism of the machine using the provided machine parameters. Force sensors were installed to measure and monitor real time changes in forging force. The machine was shut down when a forging force constituting an error value was detected, and the measured value data were saved in a cloud drive to serve as a reference for subsequent screw production.

\section{Kinematics of Mechanism}

First, kinetic theory and the parameters of the CBF-43S screw-forming machine (Table 1) were used to calculate the velocity and acceleration of each component of the slider-crank mechanism and the angular velocity and angular acceleration of the crank to provide a reference for the measurement and monitoring system.

On the basis of the schematic of the slider-crank mechanism presented in Fig. 2, the velocity of the crank was calculated as

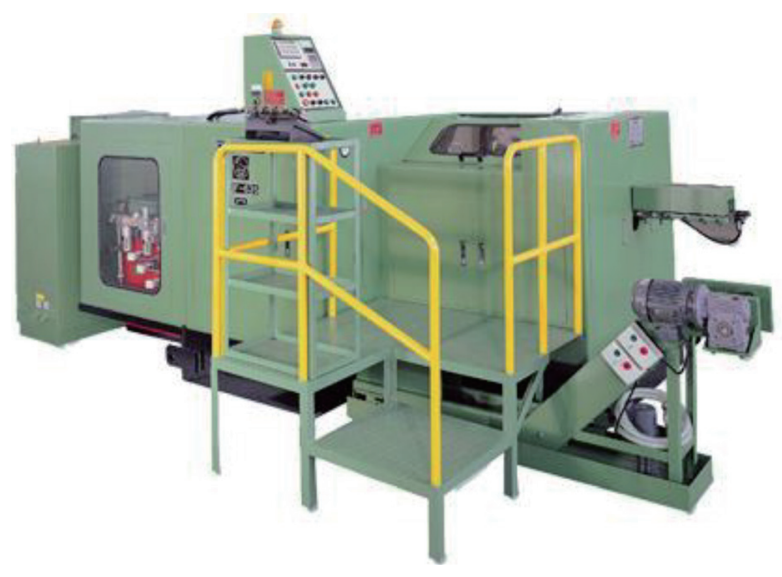

Fig. 1. (Color online) CBF-43S screw-forming machine (Chun Zu Machinery Industry). 
Table 1

Parameters of the CBF-43S screw-forming machine.

\begin{tabular}{lcc}
\hline M/C type & Unit & CBF-43S \\
\hline No. of forging stations & & 3 \\
Eccentric length of crank & $\mathrm{mm}$ & 57 \\
Mass of crank assembly & $\mathrm{kg}$ & 135.7 \\
Moment of inertia of crank assembly & $\mathrm{kg} \times \mathrm{m}^{2}$ & 1.54 \\
Length of main linkage & $\mathrm{mm}$ & 240 \\
Mass of main slider & $\mathrm{kg}$ & 108.21 \\
Forging load & $\mathrm{kg}$ & 16000 \\
Max. output & $\mathrm{pcs} / \mathrm{min}$ & 300 \\
\hline
\end{tabular}

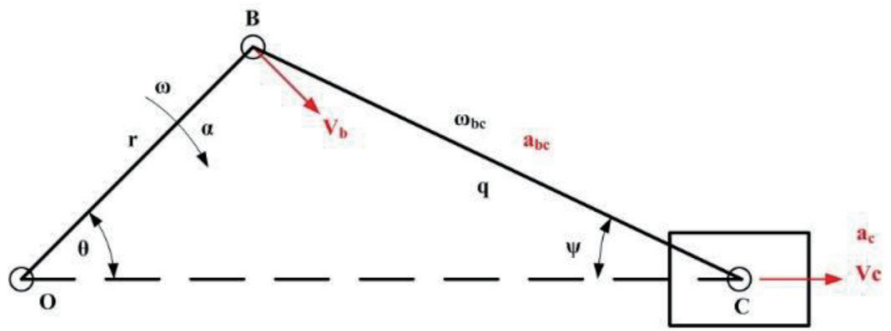

Fig. 2. (Color online) Schematic of the slider-crank mechanism.

$$
v_{b}=v_{0}+\omega \times r_{o b}
$$

The acceleration of the crank was then determined as

$$
a_{b}=a_{0}+\alpha \times r_{o b}+\omega \times\left(\omega \times r_{o b}\right) \text {. }
$$

The following calculation of the velocity of the slider was applied:

$$
v_{c}=-\omega r \sin \theta-\omega r \cos \theta \tan \theta .
$$

The angular velocity of the linkage was calculated as

$$
\omega_{b c}=\frac{-\omega r \cos \theta}{q \cos \varphi}
$$

The acceleration of the slider was represented as

$$
a_{c}=\frac{-\left(\alpha r \sin (\theta+\varphi)+\omega^{2} q r \cos (\theta+\varphi)+\omega_{b c}^{2} q\right)}{q \cos \varphi} .
$$


Finally, the angular acceleration of the linkage was calculated as

$$
a_{b c}=\frac{-\left(\alpha r \cos \theta-\omega^{2} r \sin \theta+\omega_{b c} q \sin \varphi\right)}{q \cos \varphi} .
$$

The parameters of the CBF-43S screw-forming machine were employed to calculate the rotation angle (Sida) of crank and slider positions (Fig. 3). Equations (3) and (5) were then used to determine the velocity and acceleration of the slider, respectively (Fig. 4). Finally, Eqs. (4) and (6)
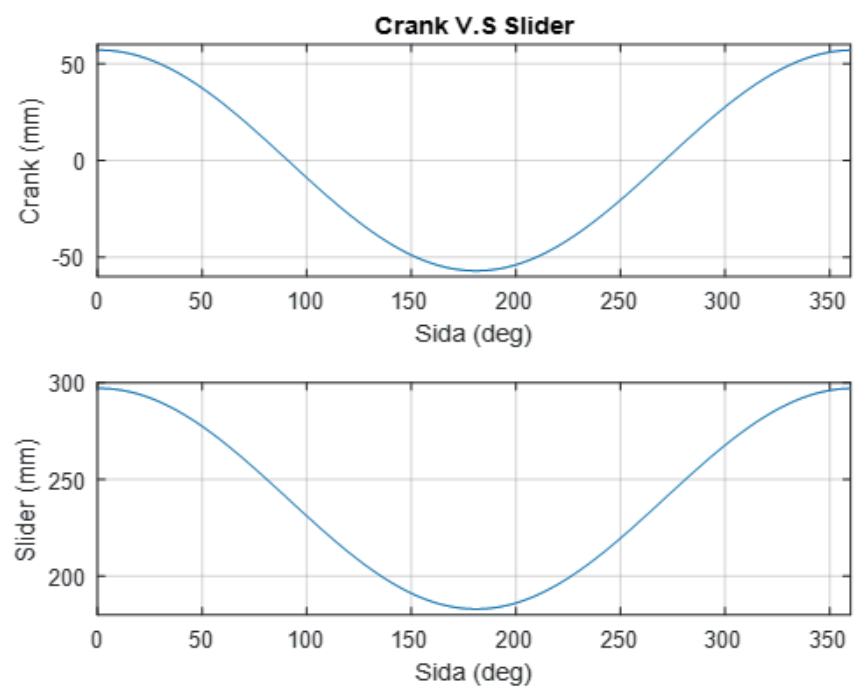

Fig. 3. (Color online) Rotation angle (Sida) of crank and slider positions.
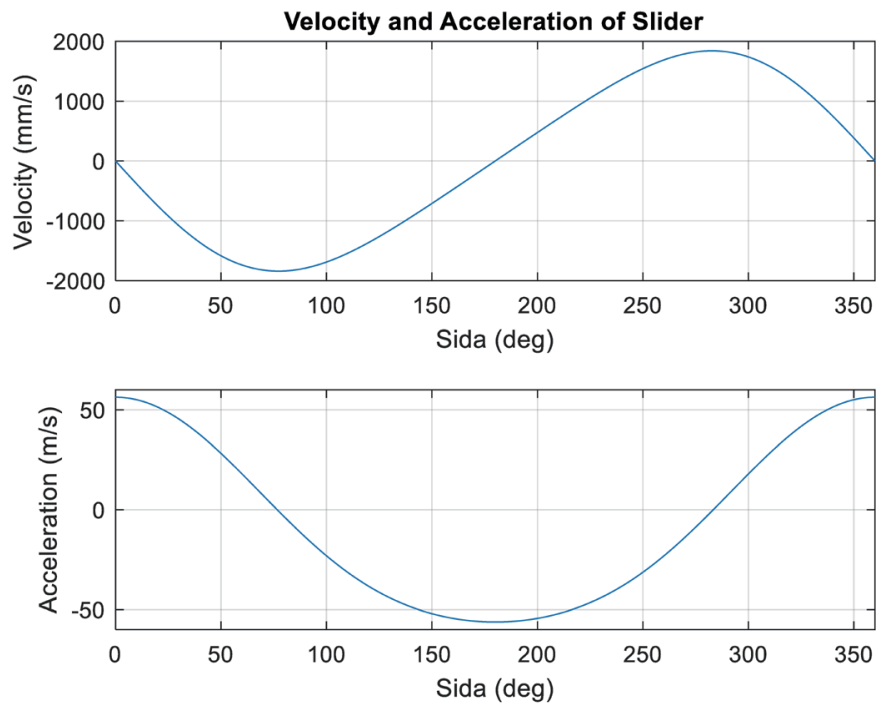

Fig. 4. (Color online) Velocity and acceleration of the slider. 
were used to calculate the angular velocity and angular acceleration of the linkage, respectively (Fig. 5).

\section{Experimental Method}

Figure 6 presents the framework for the forging force measurement experiment; the experimental instruments are listed in Table 2. The experiment was conducted using a PCB 208C05 force sensor, OMRON E2E-X4C18 2M proximity sensor, and NI Compact-DAQ chassis equipped with an NI 9234 accelerometer module and NI 9403 bidirectional digital input/output (DIO) model. Three force sensors were installed on the back side of the machine's core (Fig. 7).
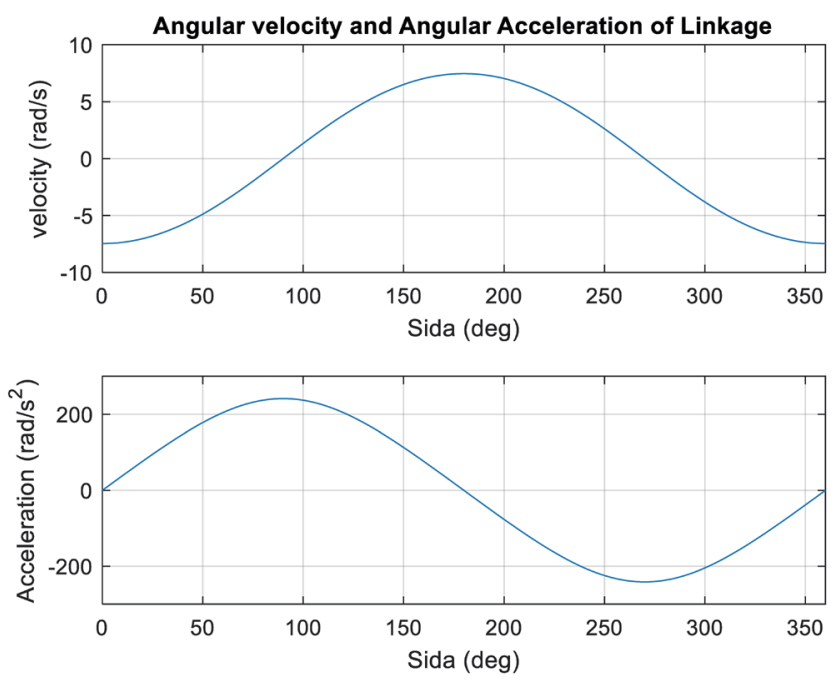

Fig. 5. (Color online) Angular velocity and angular acceleration of the linkage.

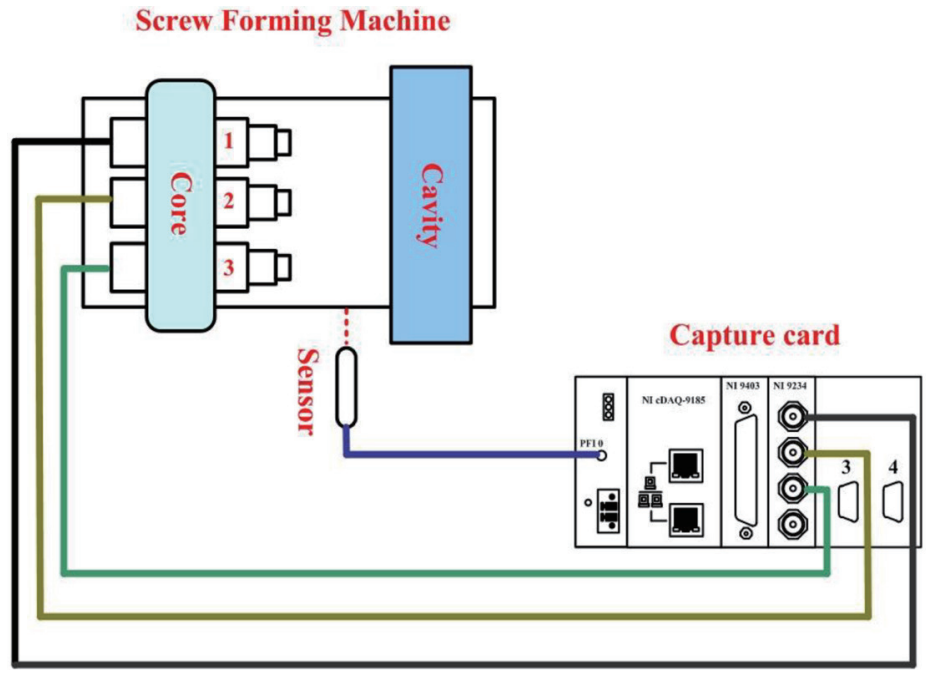

Fig. 6. (Color online) Framework of the forging force measurement experiment. 
Table 2

Instruments for the forging force measurement experiment.

\begin{tabular}{lccccc}
\hline Item & Force sensor & $\begin{array}{c}\text { Compact-DAQ } \\
\text { chassis }\end{array}$ & $\begin{array}{c}\text { Accelerometer } \\
\text { module }\end{array}$ & $\begin{array}{c}\text { Bidirectional DIO } \\
\text { module }\end{array}$ & Proximity sensor \\
\hline Model & PCB 208C05 & cDAQ-9185 & NI 9234 & NI 9403 & $\begin{array}{c}\text { OMRON } \\
\text { E2E-X4C18 2M }\end{array}$ \\
\hline
\end{tabular}

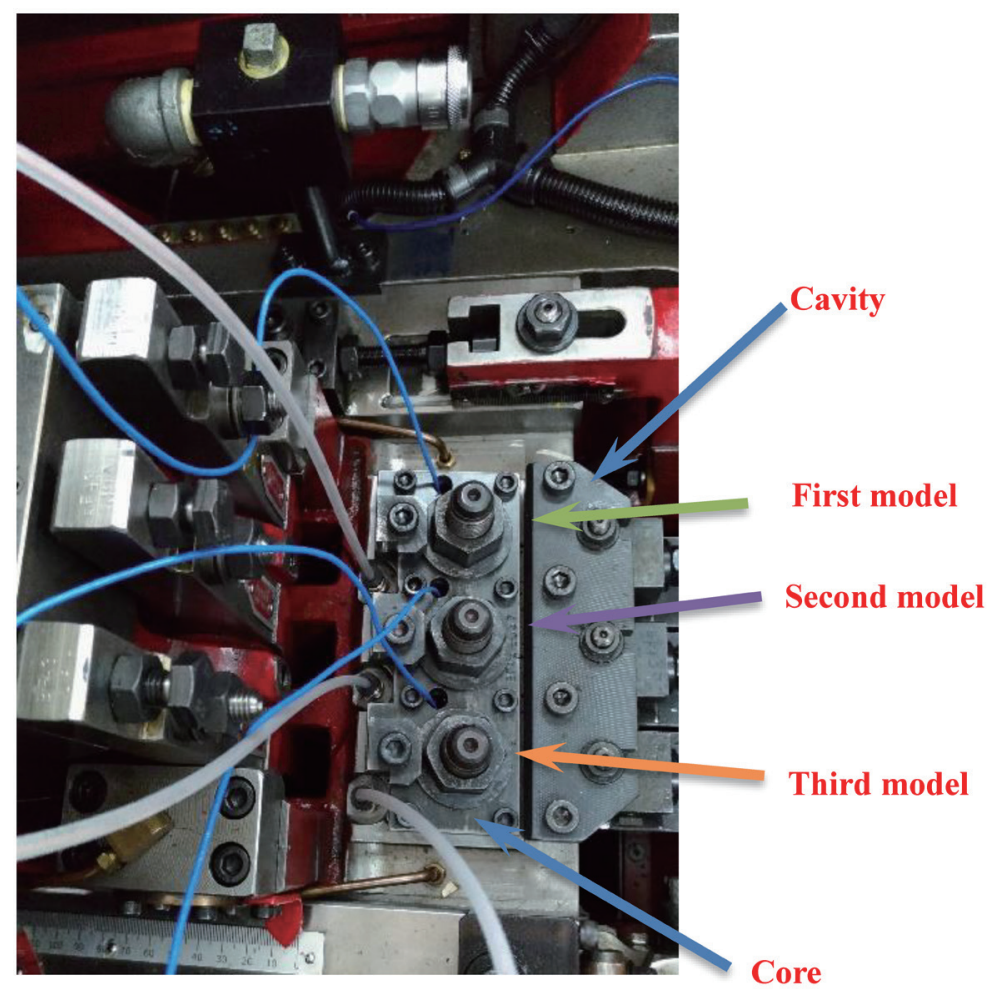

Fig. 7. (Color online) Force sensor installment positions.

The force signal was captured using the NI 9234 accelerometer module. The proximity sensor was installed above the slider; when the slider approached the sensor, the proximity sensor was activated, triggering the programmable function input (PFI) digital triggers installed on the Compact-DAQ chassis. A LabVIEW-generated diagram of the experimental framework is depicted in Fig. 8.

Figure 9 shows the program flowchart of the entire experiment. Following program activation, the number of learning cycles was set. The mean forging force achieved during learning was calculated and recorded. The computer interface was then used to set the upper and lower limits in accordance with the mean and to compare the measured forging force. When the forging force was outside the upper and lower limits, the system was immediately shut down, and an inspection was performed by the operator. After the cause of the malfunction was eliminated, the learning mode was reinitiated and the measured forging force for each cycle was 


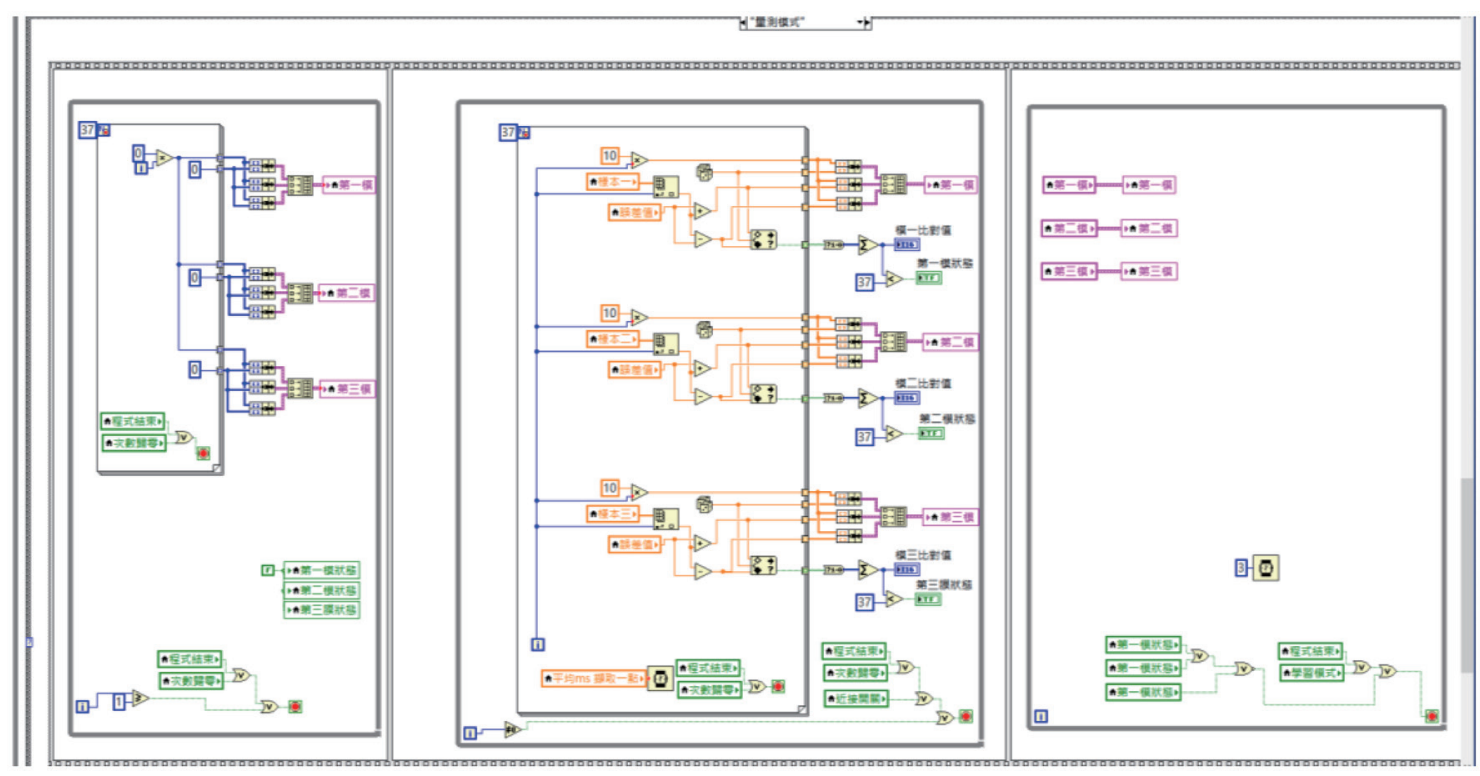

Fig. 8. (Color online) LabVIEW-generated diagram.

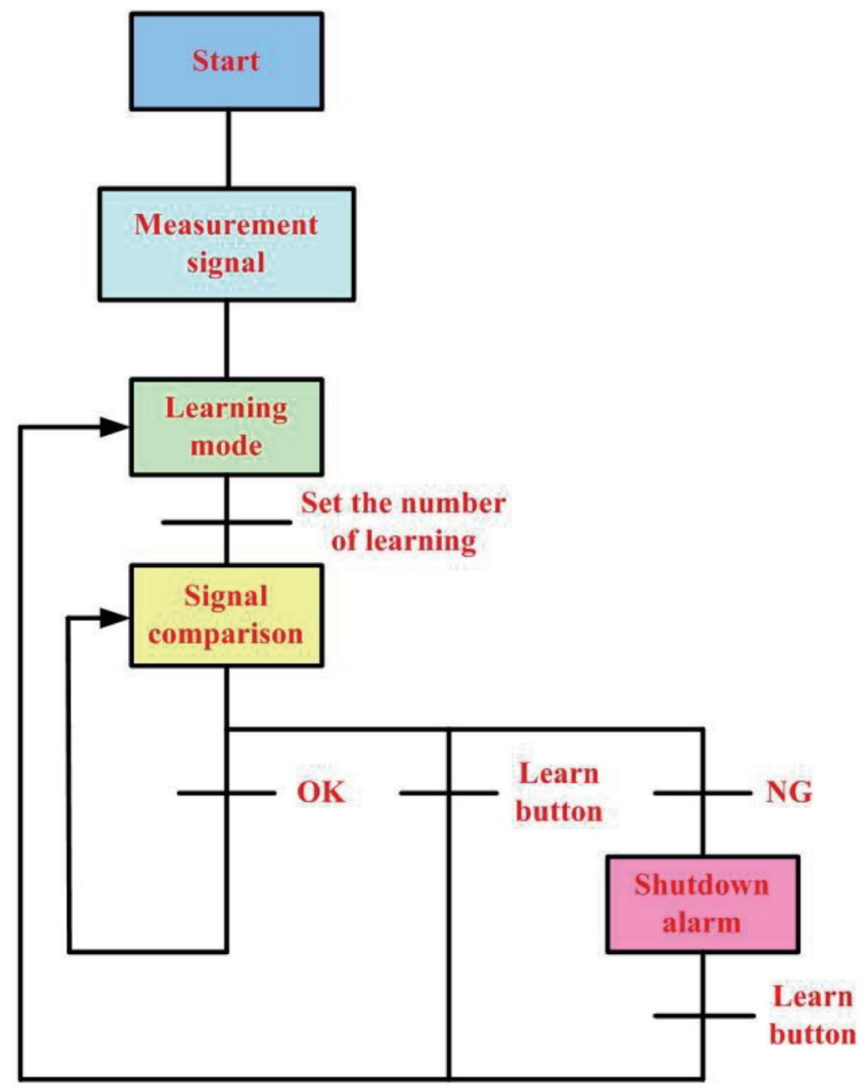

Fig. 9. (Color online) Program flowchart of the forging force measurement experiment. 
compared. Figure 10 depicts the components of the three molds; each mold was composed of a core, cavity, and forming workpiece. Figure 11 presents the proposed framework of the real time forging force measurement and monitoring system. The human-machine interface was used to activate and set the parameters of the screw-forming machine. A programmable logic controller (PLC) was employed to program the input-output points of the machine. When the forging force was outside the upper and lower limits of the mean forging force, the NI Compact-DAQ NI 9403 module transmitted a signal to the PLC to immediately shut down the screw-forming machine. During the screw forming process, the measured forging force of each mold was relayed in real time on the computer end. Through the Wi-Fi connection, the operator could monitor the condition of the screw forming machine in real time using a smartphone. Additionally, data on the system condition and the measured forging force values were saved in a cloud drive to serve as a reference for subsequent screw production.

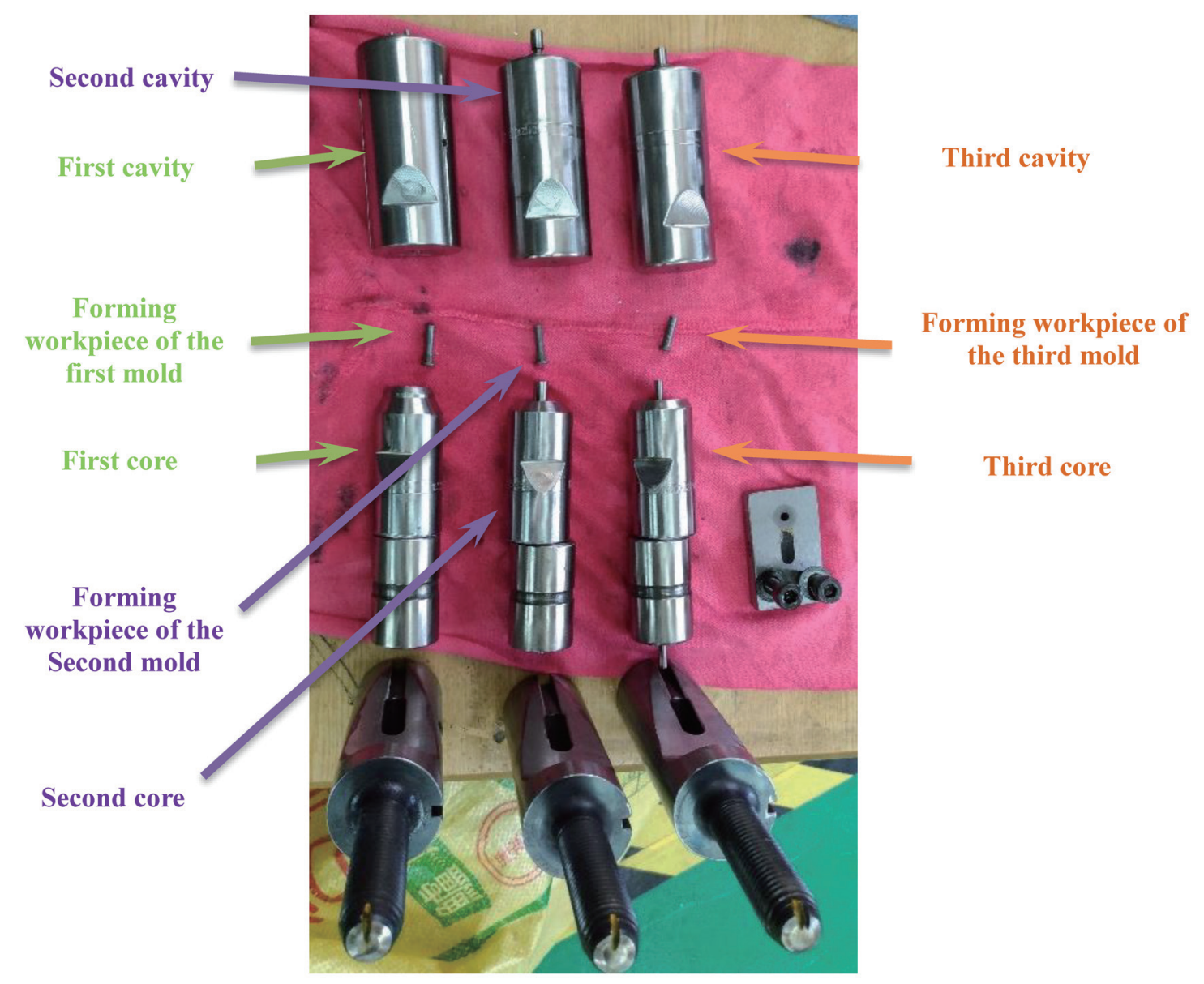

Fig. 10. (Color online) Processing components of the three molds. 


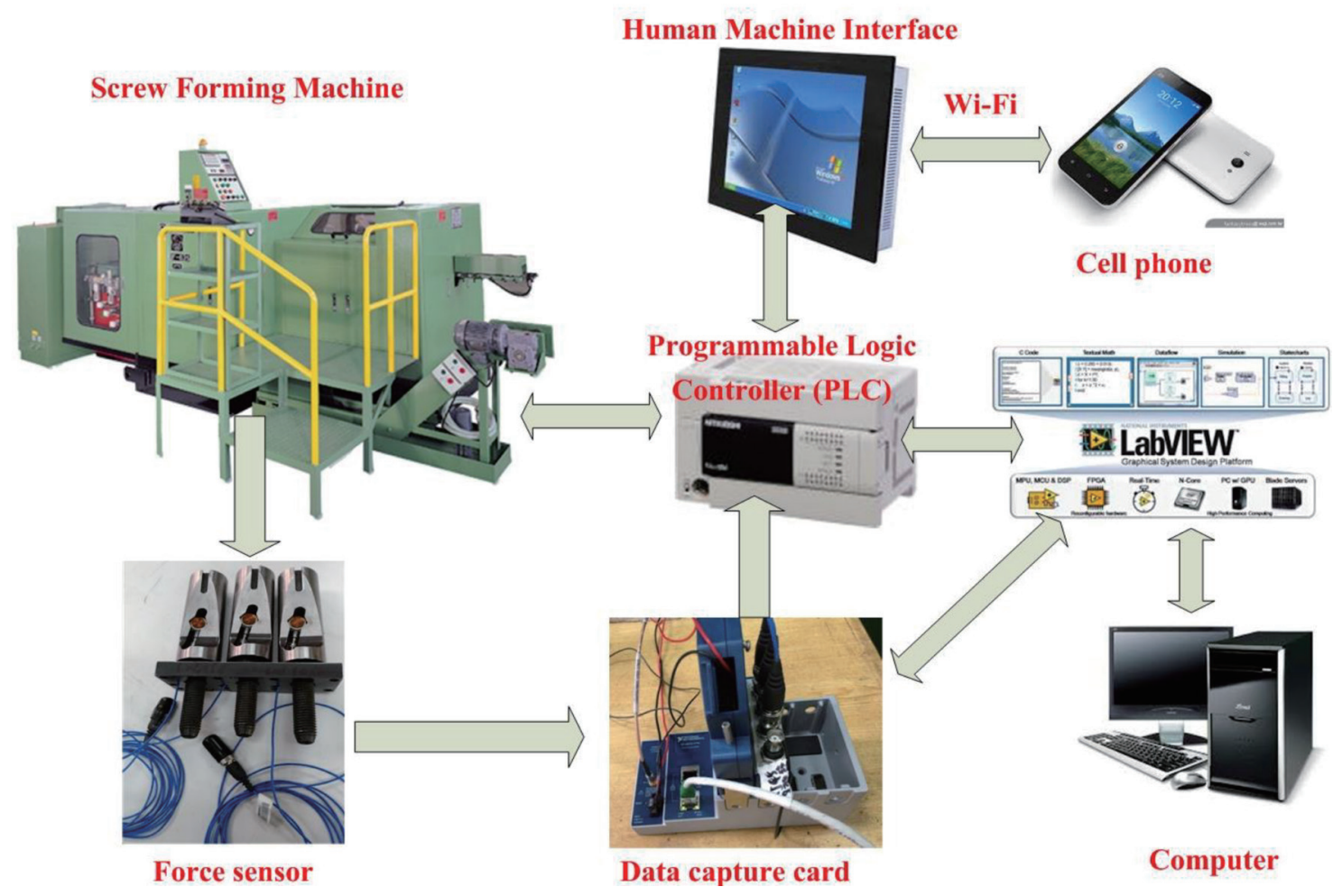

Fig. 11. (Color online) Real-time forging force measurement and monitoring system.

\section{Experimental Results and Discussion}

\subsection{Experimental results}

In the framework illustrated in Fig. 11, when the system is activated, the machine first performs testing without a workpiece to evaluate whether the measurement program is operating properly and to measure the forging force of the three molds (Fig. 12). Because the testing motor rotates at $60 \mathrm{rpm}(\mathrm{rev} / \mathrm{min})$, one screw is completed every $1 \mathrm{~s}$. Figure 13 presents the forging force values of the three molds with the workpiece. According to the figure, the screws were mainly formed in the second mold, with only a small number of screws being formed in the first and third molds.

After setting the number of learning cycles and the tolerance range based on the mean forging value, the measured forging values were compared. During the experiment, a proximity sensor was installed on the top of the slider. When the slider approached the sensor, the sensor status light on the screen lit up, and the proximity sensor triggered the PFI digital triggers installed on the Compact-DAQ chassis. Figure 8 depicts the LabVIEW-generated diagram. 


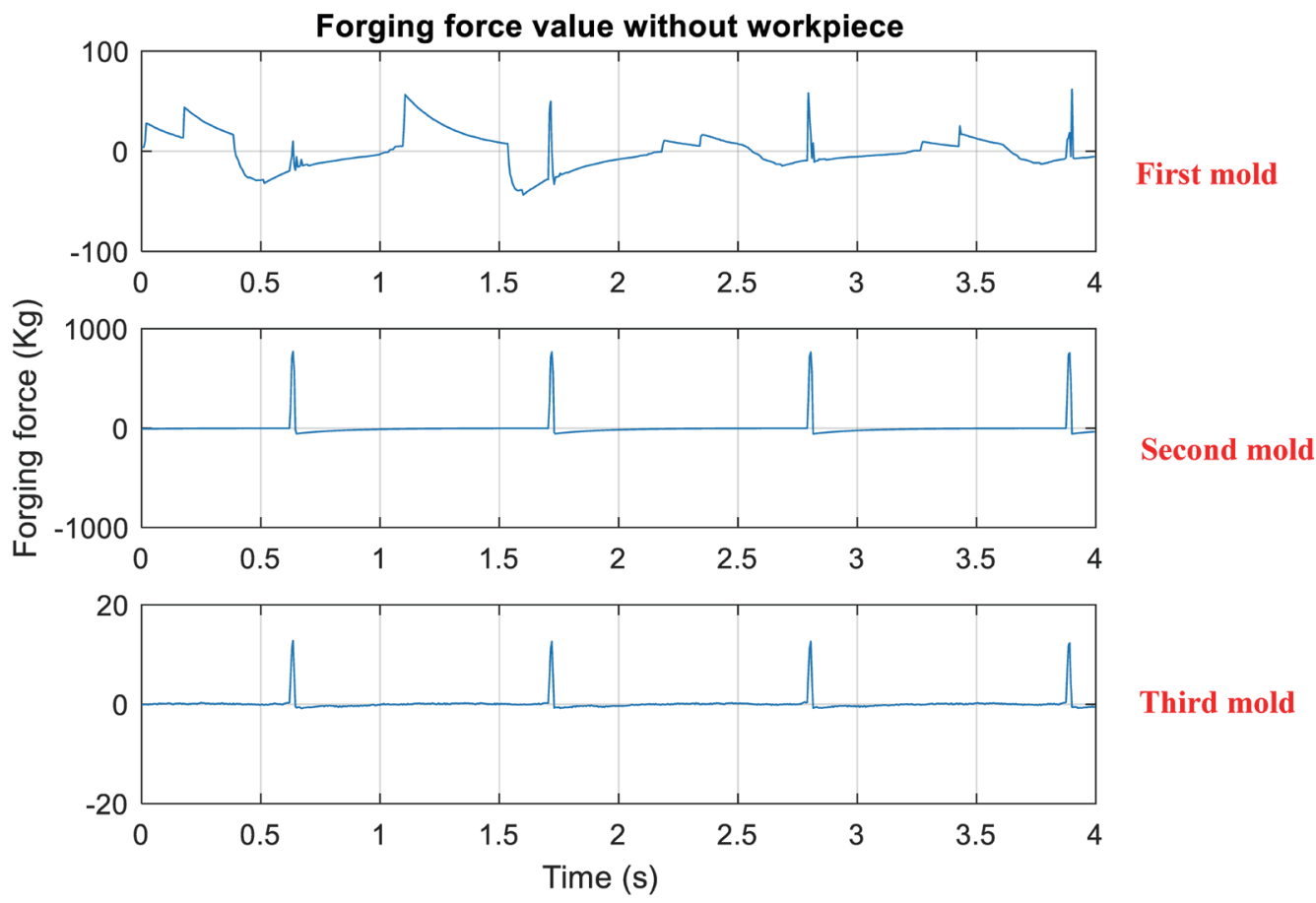

Fig. 12. (Color online) Forging force values of the three molds without a workpiece.

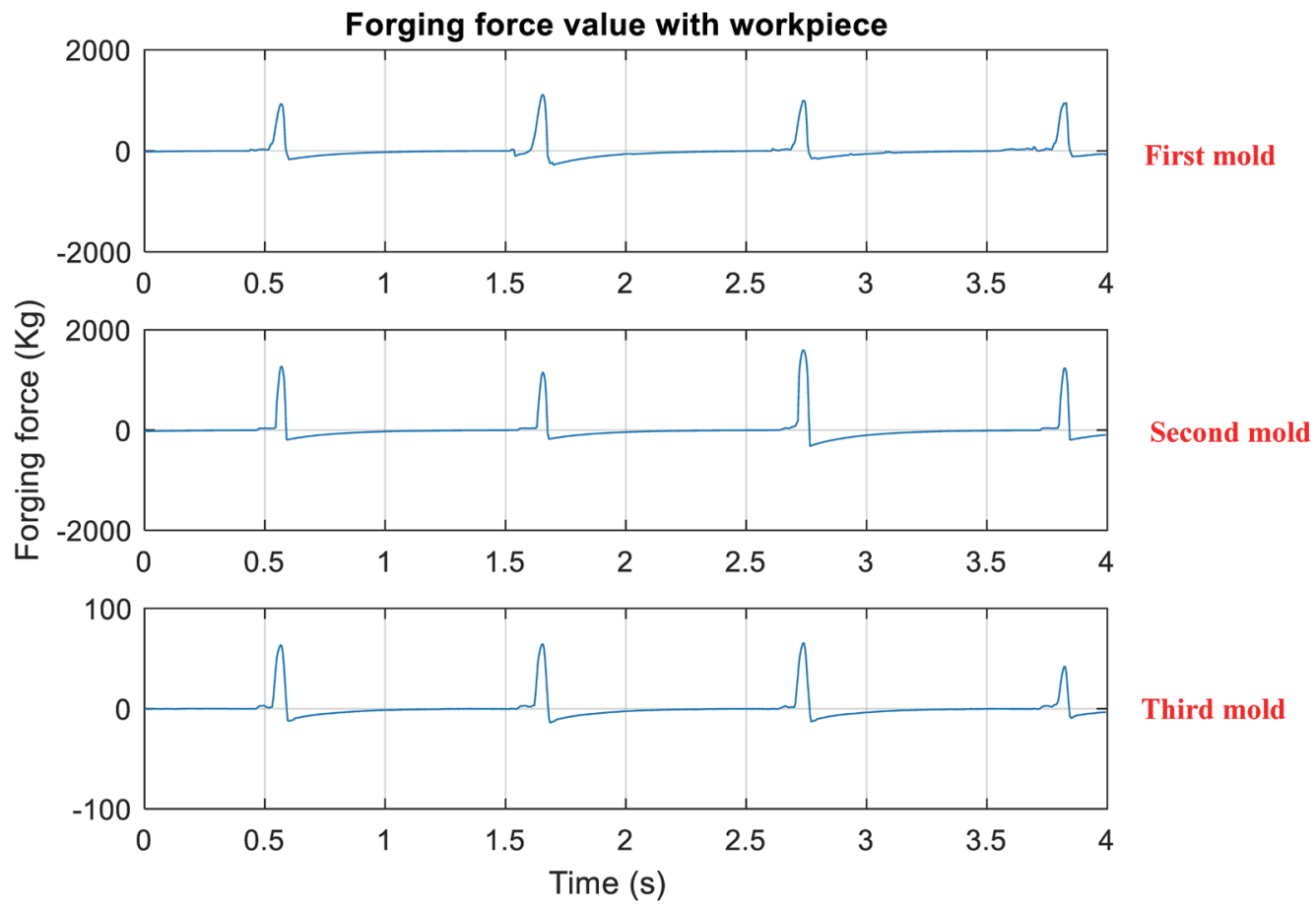

Fig. 13. (Color online) Forging force values of the three molds with the workpiece. 


\subsection{Discussion}

After each measurement cycle was completed, real time measurements of the forging force values of each mold were obtained (Fig. 14). The white solid, red dashed, and green dashed lines in Fig. 14 represent the real time measured value, upper limit, and lower limit, respectively. When the value measured in real time remained between the upper and lower limits, the screen displayed the message "Normal".

However, if the real time measured value exceeded the upper limit or decreased below the lower limit, the screen displayed the message "Error". Figure 15 presents the measured forging force when an error value was detected.

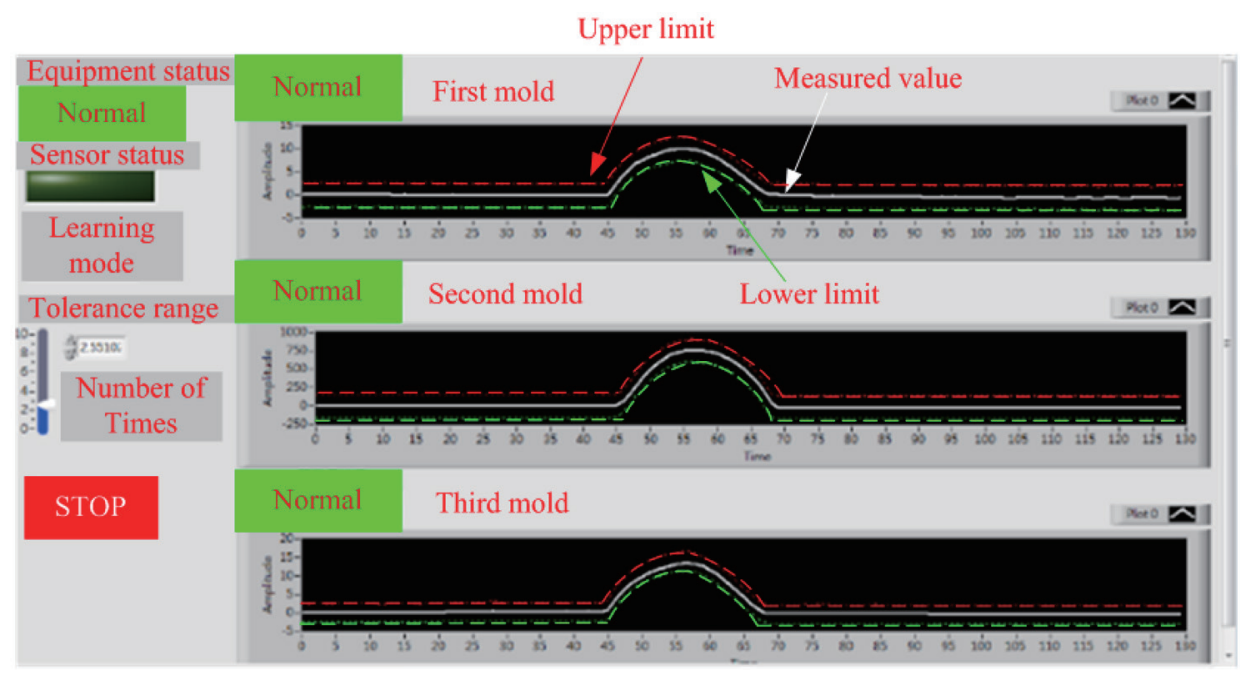

Fig. 14. (Color online) Real-time forging force measurements of the three molds.

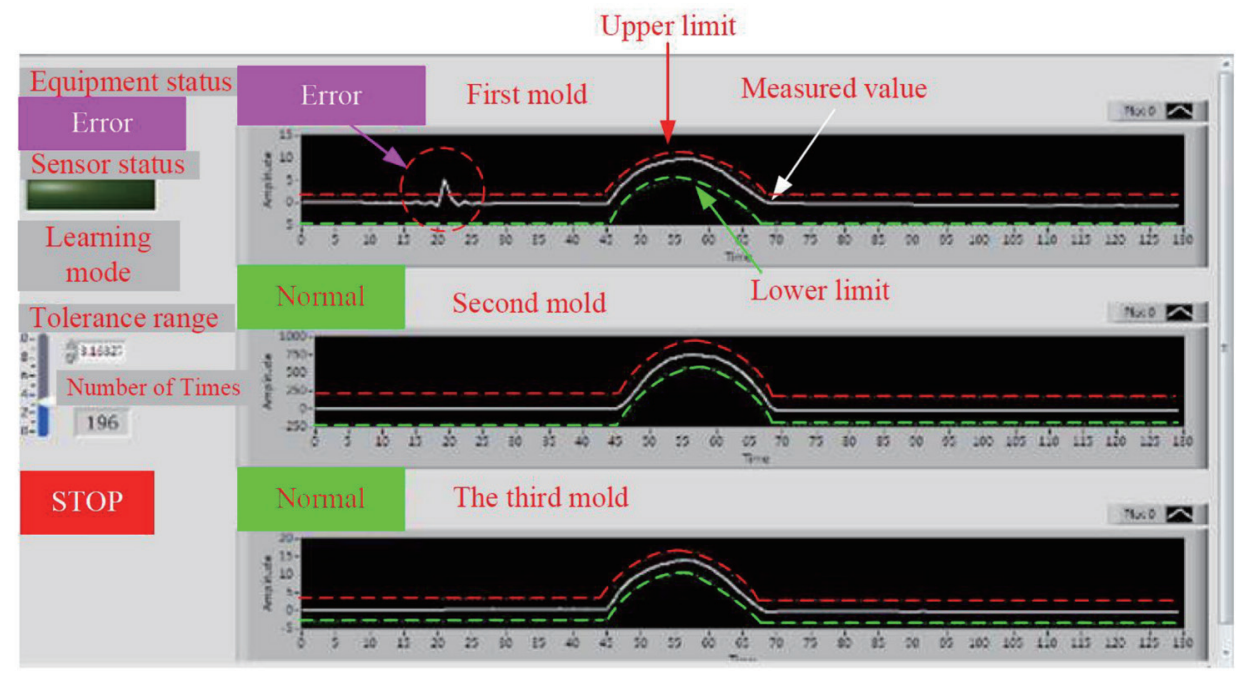

Fig. 15. (Color online) Error in the measured forging force value of the first mold. 


\section{Conclusions}

In this study, an online real time monitoring system was developed for screw-forming machines. First, kinetic analysis was performed on the slider-crank mechanism of the screwforming machine using known parameters to determine the velocity and acceleration of each component of the mechanism and the angular speed and angular acceleration of the crank. The analysis results provided reference data for the forging force measurement system.

The real time forging force measurement of three molds revealed that the measured forging force remained within the tolerance range, indicating that the machine operated normally. When an abnormal forging force was detected, the program immediately displayed an error message on the screen. As illustrated in Fig. 15, after an error value is detected in the first mold, the LabVIEW measurement program immediately transmits a signal using the NI 9403 bidirectional DIO module to the PLC to shut down machine operation. The results indicate that the proposed coupling of the NI Compact-DAQ with the LabVIEW program is effective (Figs. 14 and 15). The findings of this study offer a reference for future research on the forging force in screw-forming machines.

\section{Acknowledgments}

This work was supported by the Ministry of Science and Technology, Taiwan (grant number MOST 105-2632-E-244-001-).

\section{References}

1 S.-Y. Hsia, Y.-T. Chou, C.-C. Chang, and L.-Y. Hsu: MATEC Web Conf. 123 (2017) 00003. https://doi. org $/ 10.1051 /$ matecconf $/ 201712300003$

2 T. Yoneyama: J. Mater. Process. Technol. 95 (1999) 71. https://doi.org/10.1016/S0924-0136(99)00110-7

3 T. Yoneyama: Int. J. Adv. Manuf. Technol. 90 (2017) 2251. https://doi.org/10.1007/s00170-016-9539-7

4 C. K. Mukhopadhyay, S. Venugopal, T. Jayakumar, S. L. Mannan, Baldev Raj, B. Chatterji, R. Srinivasan, V. Gopalakrishnan, G. Madhusudan, and R. S. Tripathi: Mater. Manuf. Process. 21 (2006) 543. https://doi. org/10.1080/10426910500471698

5 I. El-Galy and B. Behrens: J. Acoust. Emiss. 26 (2008) 208. https://link.gale.com/apps/doc/A254015121/ AONE? $\mathrm{u}=$ anon $\sim 24945748 \&$ sid $=$ googleScholar\& $x i d=3$ bac $8 \mathrm{a} 60$

6 I. El-Galy and B. Behrens: 29th European Conf. Acoustic Emission Testing 09 (2010). https://www. researchgate.net/publication/263315078_Online_Monitoring_of_Hot_Die_Forging_Processes_Using_ Acoustic_Emission_Part-II

7 B.-A. Behrens, A. Santangelo, and C. Buse: Prod. Eng. 7 (2013) 423. https://doi.org/10.1007/s11740-013-0452-8

8 A. Glaeser, V. Selvaraj, K. Lee, N. Lee, Y. Hwang, S. Lee, S. Lee, and S. Min: Procedia Manuf. 48 (2020) 908. https://doi.org/10.1016/j.promfg.2020.05.129.

9 A. Glaeser, V. Selvaraj, K. Lee, N. Lee, Y. Hwang, S. Lee, S. Lee, and S. Min: Int. J. Prod. Res. 59 (2021) 4826. https://doi.org/10.1080/00207543.2021.1891318

10 I. A. Mahfouz: Int. J. Eng. Tech. Inf. 2 (2021). https://doi.org/10.51626/ijeti.2021.02.00017 